\title{
Synchrotron-Based In Situ Characterization of Carbon-Supported Platinum and Platinum Monolayer Electrocatalysts
}

\author{
Kotaro Sasaki ${ }^{1}$, Nebojsa Marinkovic ${ }^{2}$, Hugh S. Isaacs ${ }^{1}$, Radoslav R. Adzic ${ }^{1}$ \\ ${ }^{1}$ Chemistry Department, Brookhaven National Laboratory, Upton, NY 11973 \\ ${ }^{2}$ Chemical Engineering, Columbia University, New York, NY 10027
}

\begin{abstract}
A detailed understanding of oxidation/dissolution mechanisms of $\mathrm{Pt}$ is critical in designing durable catalysts for the oxygen reduction reaction (ORR), but exact mechanisms remain unclear. The present work explores the oxidation/dissolution of Pt and Pt monolayer (ML) electrocatalysts over a wide range of applied potentials using cells that facilitate in situ measurements by combining X-ray absorption spectroscopy (XAS) and X-ray diffraction (XRD) measurements. The X-ray absorption near edge structure (XANES) measurement demonstrated that Pt nanoparticle surfaces were oxidized from metallic Pt to $\alpha-\mathrm{PtO}_{2}$-type oxide during the potential sweep from $0.41 \mathrm{~V}$ to 1.5 V, and the transition state of $\mathrm{O}$ or $\mathrm{OH}$ adsorption on $\mathrm{Pt}$ and the onset of the place exchange process were revealed by the delta mu $(\Delta \mu)$ method. Only the top layers of Pt nanoparticles were oxidized, while the inner $\mathrm{Pt}$ atoms remained intact. At higher potential over $1.9 \mathrm{~V}, \alpha-\mathrm{PtO}_{2}$-type surface oxides dissolve due to local acidification caused by the oxygen evolution reaction and carbon corrosion. Pt oxidation of $\mathrm{Pt}_{\mathrm{ML}}$ on $\mathrm{Pd}$ nanoparticle electrocatalyst is considerably hampered compared with the $\mathrm{Pt} / \mathrm{C}$ catalyst, presumably because preferential Pd oxidation proceeds at the defects in Pt MLs up to
\end{abstract}


$0.91 \mathrm{~V}$ and through $\mathrm{O}$ penetrated through the Pt MLs by the place exchange process above $1.11 \mathrm{~V}$.

\section{Keywords}

carbon-supported platinum nanoparticles, platinum monolayer catalyst, in situ X-ray absorption spectroscopy, in situ X-ray diffraction, platinum oxides, place-exchange process 


\section{INTRODUCTION}

At present platinum offers the best catalyst for both the anodic and cathodic reactions for low temperature proton exchange membrane fuel cells (PEMFCs). However, its catalytic activity degrades following oxidation of the surface. It is known that the gradual decline in performance of PEMFCs is caused by the dissolution of carbon-supported Pt nanoparticles at the cathode during potential cycling, resulting in the loss of the electrochemical surface area. ${ }^{1-4}$ Platinum dissolution occurs not only anodically during positive-going sweeps, but also cathodically during negative-going sweeps in acid electrolyte. $^{5,6}$ A detailed understanding of oxidation/dissolution mechanisms of Pt is therefore essential in developing highly stable catalysts for the oxygen reduction reaction (ORR).

The surface oxidation of bulk Pt is one of the most studies precious metal-oxide systems. Conway et al. ${ }^{7,8}$ summarized earlier work on Pt oxide formation; in the potential region of $0.85 \mathrm{~V}-1.10 \mathrm{~V}$ in an $\mathrm{H}_{2} \mathrm{SO}_{4}$ solution, adsorbed $\mathrm{OH}$ species are formed by the oxidation of $\mathrm{H}_{2} \mathrm{O}$ molecules (reaction 1). The $\mathrm{OH}$ and $\mathrm{Pt}$ surface atoms then undergo placeexchange, forming a quasi-3D lattice (reaction 2). At higher potentials (1.10-1.40V), the $\mathrm{OH}$ species in this lattice are oxidized, generating a Pt-O quasi-3D lattice (reaction 3).

$$
\begin{aligned}
& \mathrm{Pt}+\mathrm{H}_{2} \mathrm{O} \rightarrow \mathrm{Pt}-\mathrm{OH}+\mathrm{H}^{+}+\mathrm{e}^{-} \quad(0.85 \mathrm{~V}<E<1.10 \mathrm{~V}) \\
& \mathrm{Pt}-\mathrm{OH} \stackrel{\text { place exchange }}{\longrightarrow}(\mathrm{OH}-\mathrm{Pt})_{\text {quasi-3D lattice }} \\
& (\mathrm{OH}-\mathrm{Pt})_{\text {quasi-3D lattice }} \rightarrow(\mathrm{Pt}-\mathrm{O})_{\text {quasi-3D lattice }}+\mathrm{H}^{+}+\mathrm{e}^{-} \quad(1.10 \mathrm{~V}<E<1.40 \mathrm{~V})
\end{aligned}
$$


More recent studies suggested that the Pt oxides are not hydrated, ${ }^{9-11}$ and at $0.85-1.15 \mathrm{~V}$ a half-monolayer (0.5ML) forms from chemisorbed $\mathrm{O}$, rather than $\mathrm{OH}$. Above a potential of $1.15 \mathrm{~V}$, the $\mathrm{O}$ adatoms undergo place-exchange with platinum atoms. ${ }^{12}$

At higher potentials over $1.40 \mathrm{~V}$ and prolonged polarization time, $\mathrm{PtO}_{2}$ grows on the top of the PtO layer (reaction 4). ${ }^{7,8}$ The growth of the PtO layer is confined to a thickness of $2 \mathrm{MLs}$, while $\mathrm{PtO}_{2}$ growth is unlimited at a significantly high rate on the PtO layer.
$\mathrm{PtO}+\mathrm{H}_{2} \mathrm{O} \rightarrow \mathrm{PtO}_{2}+2 \mathrm{H}^{+}+2 \mathrm{e}^{-}$
$(E>1.40 \mathrm{~V})$

When the potential decrease between $0.60 \mathrm{~V}$ and $0.30 \mathrm{~V}$, PtO is preferentially reduced under the $\mathrm{PtO}_{2}$ layer, thereby leading to $\mathrm{PtO}_{2}$ residing on the $\mathrm{Pt}$ substrate. Subsequent reduction $\mathrm{PtO}_{2}$ to Pt occurs at lower potentials between $0.30 \mathrm{~V}$ and $0.10 \mathrm{~V}$. $^{7,8}$

In situ X-ray Absorption Spectroscopy (XAS) techniques, including extended X-ray absorption fine structure (EXAFS) and X-ray absorption near edge structure (XANES), offer a unique ability to investigate both electronic and structural properties of electrocatalysts; the information obtained is essential for elucidating the atomic arrangement, the degree of oxidation, and the effects of metal-oxide substrates on electronic properties of catalysts, in relation to their catalytic activity. Previous in situ XAS analyses of Pt nanoparticle electrocatalysts have reported oxidation process on $\mathrm{Pt}$ nanoparticles by monitoring $\mathrm{Pt} \mathrm{L}_{3}$ spectra at different potentials. ${ }^{13-19}$ However, interpretations of the oxide growth (from adsorbed $\mathrm{OH}$ or $\mathrm{O}$ to oxide $\mathrm{PtO}$ or $\mathrm{PtO}_{2}$ ) differ and mechanisms for oxidation/degradation of Pt nanoparticles with elevating potentials are still unclear.

Here we report the changes in the oxidation process of Pt nanoparticle electrocatalysts using two different cells for in situ electrochemical measurements ${ }^{20,21}$; one cell allows us 
to measure XAS and XRD of the same sample at the same electrochemical potentials, while the other cell provides XAS measurements over a wider range of applied potentials to 2.6 V. We have also investigated oxidation behavior of Pt ML electrocatalysts that achieved a dramatically reduced Pt content while affording considerable possibilities for enhancing their catalytic activity and stability. ${ }^{22}$ We demonstrated that Pt oxidation of Pt ML electrocatalysts is considerably reduced compared with Pt/C catalysts. Plausible origins of the enhanced stability are discussed.

\section{EXPERIMENTAL SECTION}

Catalysts A commercial carbon-supported Pt nanoparticle catalyst (46 wt-\%, Pt from TKK Corp., Japan) was utilized for in situ XAS and XRD measurements. The average diameter of the Pt/C sample is $2.6 \mathrm{~nm}$ (Figure 3c). A carbon-supported Pt ML on Pd nanoparticle catalyst $\left(\mathrm{Pt}_{\mathrm{ML}} / \mathrm{Pd} / \mathrm{C}\right)$ was synthesized by the galvanic displacement of a

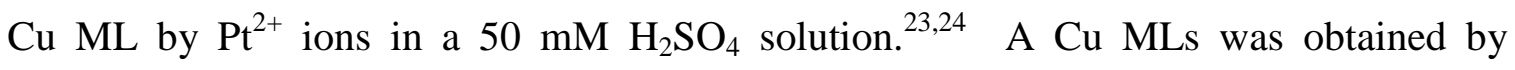
underpotential deposition (UPD) of a $\mathrm{Cu}$ ML on the reduced surfaces of carbonsupported Pd nanoparticles (30 wt-\% Pd) that were purchased from N.E. Chemcat Corp., Japan. The procedure of 2 gram synthesis was described elsewhere. ${ }^{20}$ STEM/EDS measurements were carried out using a JEM 2100F microscope. The mean diameter of the nanoparticles was determined $4.2 \mathrm{~nm}$ (Figure $\mathrm{S} 1$ (SI)). A commercial $\mathrm{PtO}_{2}$ powder was purchased from Alfa Aesar, MA (99.99\%, Product \#: 40402). The XRD pattern of the $\mathrm{PtO}_{2}$ power is depicted in Figure S2. The structure of $\mathrm{PtO}_{2}$ was identified to a hexagonal phase of $\alpha-\mathrm{PtO}_{2}$ (JCPDS 38-1355). ${ }^{25}$ The $\mathrm{PdO} / \mathrm{C}$ sample was made by annealing the commercial $\mathrm{Pd} / \mathrm{C}$ catalyst at $350^{\circ} \mathrm{C}$ for $2 \mathrm{~h}$ in air. The XRD pattern of the 
obtained PdO/C powder is shown in Figure S3, and the structure of PdO was determined to a tetragonal phase (JCPDS 75-0584).

X-ray measurements XAS measurements using two different electrochemical cells (termed as cell I and cell II) were undertaken at the X18A, X18B, and X19A beamlines at the National Synchrotron Light Source (NSLS) at Brookhaven National Laboratory (BNL), as well as at the B2-2 beamline at the Stanford Synchrotron Radiation Lightsource (SSRL) at SLAC National Accelerator Laboratory.

Electrochemical cell I: The first cell used for the in situ electrochemical measurements was a modified version of the one described by McBreen et al., ${ }^{26}$ and was described in elsewhere. ${ }^{18,19}$ The cell allows XAS data acquisition in both transmission and fluorescence modes, although the data presented below were acquired in the transmission mode. A carbon cloth, carbon-supported catalyst (ca. $3 \mathrm{mg}_{\mathrm{Pt}} / \mathrm{cm}^{2}$ ), proton exchange membrane (Nafion 117, DuPont Chemical Co., DE), and two PTFE gaskets were sandwiched together and inserted in the thicker plastic body (Figure 1a). All those components were clamped tightly in a space between two acrylic plastic bodies and an Oring. The space was filled with an electrolyte of $1 \mathrm{M} \mathrm{HClO}_{4}$. Each plastic body has an X-ray window that is glued by a thin acrylic film. A Pt foil on the thicker plastic body acts as a counter electrode, while a Pt ribbon on the thinner plastic body achieves electrical contact with the electrocatalyst (working electrode) through the carbon cloth. Two capillaries are drilled in the thicker plastic block; one is used for adding electrolyte into the cell, whereas the other provides a contact of the solution with an Ag/AgCl leakfree reference electrode. 
The electrochemical cell also allows us to measure XRD at controlled electrochemical potentials. XRD experiments were performed at Beamline X18A at NSLS. The XRD spectra were recorded using a 2D detector (Perkin Elmer XRD $1621 \mathrm{~N} \mathrm{ES}$ ) at $12.4 \mathrm{keV}$ and subsequently processed using standard data processing software. The dark current and the diffraction pattern were collected over 40 seconds (10 exposures at $4 \mathrm{~s}$ each) and the diffraction pattern was recorded over 400 seconds (100 exposures at $4 \mathrm{~s}$ per exposure). The wavelength of X-ray used was $1.000 \AA$.

Electrochemical cell II: The second cell ${ }^{30,31}$ with its working electrode is illustrated in Figure $1 \mathrm{~b}$. The working electrode consists of the Pt/C catalyst $\left(c a .30 \mu \mathrm{g}_{\mathrm{P}} / \mathrm{cm}^{2}\right)$ on a carbon fiber paper that acted as the catalyst support. The working electrode was placed behind a thin Mylar film $(10 \mu \mathrm{m})$ that covered a window of the cell. The electrode was in contact with a $0.1 \mathrm{M} \mathrm{HClO}_{4}$ bulk solution (ca. $50 \mathrm{ml}$ ) in a plastic container. The incident X-ray beam is directed onto the sample through the Mylar film, and the resultant fluorescence intensity is monitored by a passivated implanted planar silicon (PIPS) detector. The electrolytes in both the cell I \& II were not deaerated. All potentials in this paper are quoted with respect to the reversible hydrogen electrode (RHE). The data acquired by both the electrochemical cells were processed and analyzed by Athena software. ${ }^{27}$

\section{RESULTS AND DISCUSSION}

\section{In situ XANES for Pt oxidation of carbon-supported Pt nanoparticles}

Figure 2 shows in situ XANES spectra for $\mathrm{Pt}_{\mathrm{L}}$ edge of carbon-supported $\mathrm{Pt}$ nanoparticles at potentials ascending from $0.41 \mathrm{~V}$ to $1.51 \mathrm{~V}$ (Figure 2a), followed by 
descending from $1.51 \mathrm{~V}$ to $0.41 \mathrm{~V}$ in $1 \mathrm{M} \mathrm{HClO}_{4}$ (Figure 2b). Each XANES was acquired 40 min after the potential was set to a certain value. Also shown in the figure is an ex situ XANES spectrum of a commercial $\mathrm{PtO}_{2}$ sample. On increasing the potential, the intensity of the white line increases and the adsorption peaks are shifted to higher energies as a consequence of depleting Pt's $d$-band due to the Pt oxide formation. They start to decrease with declining potentials as a result of filling $d$-band due to reduction of the oxide. The intensity of the white line at $0.41 \mathrm{~V}$ is almost identical before and after the potential cycling, but irreversible reduction during descending potentials gives hysteresis in a relative change of white line intensity. This indicates that the potential for oxide reduction is lower than that for oxide formation. Figure 2c depicts such the hysteresis with respect to that at double layer region $\left(\left(\Delta \mu_{\mathrm{E}}-\Delta \mu_{0.41 \mathrm{~V}}\right) / \Delta \mu_{0.41 \mathrm{~V}}\right.$, see Figure S4) observed in potential cycles with different upper potentials. A similar hysteresis was reported elsewhere. ${ }^{16,19}$

Three distinct isosbestic points at $11573 \mathrm{eV}, 11603 \mathrm{eV}$, and $11624 \mathrm{eV}$ are observed in the XANES from all the Pt/C and the $\mathrm{PtO}_{2}$ samples, indicating the existence of Pt species in two different chemical forms, having the same total concentration. The change observed demonstrated that the surface of Pt nanoparticles is oxidized from metallic Pt (at $0.41 \mathrm{~V}$ ) to a form of $\alpha-\mathrm{PtO}_{2}$ as the potential increases; no clear intermediates are visually seen in the XANES spectra.

The electrochemical cell I (Figure 1a) allows us to measure XAS and XRD of the same sample at the same electrochemical potentials. In situ XRD from the same specimen was measured immediately after the XAS at each electrochemical potential (Figure 3a). The XRD patterns showed fairly small broadening of the peaks with increasing potentials, and 
there is no indication of reflections from $\alpha-\mathrm{PtO}_{2}$. A marked feature is that the particle size, which is determined by Sherrer's equation, changes from $2.6 \mathrm{~nm}$ to $2.1 \mathrm{~nm}$ by applying potentials from 0.41 to $1.51 \mathrm{~V}$ (Figure 3c), indicating that the most outer layer of Pt particles is oxidized. Although the potential to $1.51 \mathrm{~V}$ significantly enhances the white line due to oxidation, the oxide film is formed with Pt atoms only in the surface layer on the nanoparticles. Thus the thickness of the oxide film is too thin to produce the diffraction patterns. As shown in detailed patterns of the Pt(2 20$)$ reflection (Figure 3b), the peak positions slightly shifts to lower angles with an increase in potential; this shift is supposed to be caused by the formation of $\alpha-\mathrm{PtO}_{2}$ oxide having a longer Pt-Pt bonding distance (ca $3.13 \AA)$.

We employ the linear composition analysis (LCA) technique to determine the fraction of metallic Pt and $\mathrm{PtO}_{2}$ components from the XANES at different potentials. The best fitting combination using reference spectra by the least mean square method gives the percentages of the respective components in the sample. As one of fitting examples, the $\mathrm{Pt} \mathrm{L}_{3}$ XANES from Pt/C at $1.31 \mathrm{~V}$, together with those of oxide-free $\mathrm{Pt} / \mathrm{C}$ at $0.41 \mathrm{~V}$ and commercial $\mathrm{PtO}_{2}$, are shown in Figure 4a. The fitting by the LCA technique determined that the molar content of $\mathrm{Pt}$ metal and $\mathrm{PtO}_{2}$ is $74 \%$ and $26 \%$, respectively. $\mathrm{PtO}_{2}$ percentage (\%) involved in the catalyst as a function of applied potentials is shown in Figure $4 \mathrm{~b}$. The ratio of surface atoms $\left(\mathrm{N}_{\mathrm{s}}\right)$ to total atoms $\left(\mathrm{N}_{\mathrm{t}}\right)$ is a function of particle size, and the $\mathrm{N}_{\mathrm{s}} / \mathrm{N}_{\mathrm{t}}$ is $c a .0 .52$ for icosahedron and cuboctahedron nanoparticles with a diameter of $2.6 \mathrm{~nm}$ (Table S1). This indicates that $76 \%$ of surface Pt atoms were oxidized at $1.51 \mathrm{~V}$, assuming that the oxidation takes place only at the top layer of the nanoparticles as indicated by in situ XRD (Figure 3c). The result from the cyclic 
voltammograms also agrees reasonably well with those from in situ XANES and XRD measurements (Figure S5).

In situ XANES revealed that Pt nanoparticles are oxidized from a metallic state at $0.41 \mathrm{~V}$ to a $\mathrm{PtO}_{2}$-type oxide structure during the potential excursion up to $1.51 \mathrm{~V}$. Although the changes in the XANES spectra caused by the adsorbate formation and the place exchange process are considered to be subtle, they could be amplified and be analyzed by the delta mu $(\Delta \mu)$ method. The $\Delta \mu$ technique has been developed as a surface sensitive method to identify surface/adsorbate interactions. ${ }^{28-30}$ By subtracting spectra of a sample at two different potentials, the $\Delta \mu$ method isolates surface/adsorbate interactions since bulk metal-metal interactions are approximately eliminated by the subtraction. The obtained $\Delta \mu$ spectra are interpreted by comparing with theoretical $\Delta \mu$ curves based on crystallographic models. Figure 5 depicts the $\Delta \mu$ spectra of the Pt/C catalyst at $E=0.71$ $\mathrm{V}, 0.91 \mathrm{~V}$, and $1.11 \mathrm{~V}$, calculated using the equation $(\Delta \mu(E)=\mu(E)-\mu(0.41 \mathrm{~V}))$, where $\mu(0.41 \mathrm{~V})$ is the reference curve of $\mathrm{Pt} / \mathrm{C}$ considered free from any adsorbates on the $\mathrm{Pt}$ surface. The $\Delta \mu(0.71 \mathrm{~V})$ shows a small positive peak at a few $\mathrm{eV}$ above the edge energy $E_{0}\left(11564 \mathrm{eV}\right.$ for Pt $\mathrm{L}_{3}$ edge). With a further increase in potential, the intensity of $\Delta \mu$ increases and the peak position shifts slightly toward higher energy values. The observation is interpreted as the initiation of $\mathrm{O}$ or $\mathrm{OH}$ adsorption in atop sites of $\mathrm{Pt}$ at $0.71 \mathrm{~V}$, followed by n-fold bonded configuration at higher potentials. Another intriguing feature is that a negative peak slightly below the $E_{0}$ starts to discernably appear $\geq 0.91 \mathrm{~V}$, which is ascribed to the formation of subsurface $\mathrm{O}$ due to a "place-exchange” process, as indicated by comparison to the theoretically calculated $\Delta \mu$ spectral signatures. ${ }^{28,29}$ It is generally accepted that the interfacial place exchange between the adsorbed $\mathrm{O}$ and $\mathrm{Pt}$ 
atoms takes place at higher potentials than $1.1 \mathrm{~V}$ in deaerated electrolytes. ${ }^{11,12,31}$ However, it was demonstrated that place-exchange can take place on Pt surfaces at much lower potentials such as $0.75 \mathrm{~V}$ when solutions are aerated, ${ }^{18}$ which is in line with the present observation.

Combined XAS and XRD measurements demonstrated that only the most outer layer of Pt surface is oxidized at potentials up to $1.5 \mathrm{~V}$, and this results in the formation of 2 layers of $\mathrm{PtO}_{2}$ on the surfaces after the place-exchange process; however, as mentioned in the INTRODUCTION, some studies reported that thicker $\mathrm{PtO}_{2}$ oxides can be formed on bulk Pt at higher potentials above $1.6 \mathrm{~V},{ }^{7-11}$ it is thus curious to reveal whether Pt atoms in inner layers of Pt nanoparticles can be oxidized at higher potentials. The cell I can be used for in situ electrochemical measurements with applied potentials up to $1.6 \mathrm{~V}$; above 1.6 V, the oxygen evolution and hydrogen evolution reactions may occur on the working and counter electrodes, respectively, and the gas evolution induces physical motion of the catalyst layer inside the cell (as the cell components with an electrolyte are tightly clamped by two plastic bodies to minimize absorption by the electrolyte), resulting in serious deterioration in signal quality.

We have also employed the other type of cell II, in which the catalyst on a carbon paper is subject to an ample electrolyte solution and the counter electrode is located relatively far from the catalyst electrode (Figure 1b). ${ }^{32}$ With this configuration, a gas evolved on the catalyst surfaces can be easily released upward through the solution and within the carbon paper, and thus the fluorescence signal is not influenced by disturbance induced by the gas. With the cell II, in situ XANES of the Pt/C catalyst was recorded from 0.47 $\mathrm{V}$ to $2.57 \mathrm{~V}$. The intensity of the white line increases with elevating potentials in a 
similar manner observed with the cell I up to $1.5 \mathrm{~V}$. Interestingly, after attaining the maximum intensity around $1.9 \mathrm{~V}$, the intensity started to decrease at higher potentials as shown in Figure 6. The change in white line intensity with the applied potentials (red curve in Figure 7) shows this trend more clearly. It appears that the amount of Pt oxide decreased at the higher potentials above $1.9 \mathrm{~V}$.

We then examined changes in edge height of the spectra; in the present analysis the edge height was taken as the difference in raw absorption coefficient between pre-edge and post-edge lines at $11620 \mathrm{eV}$ (Figure S6). For a thin layer sample with carbon-supported nanoparticles, where the beam passes through the entire sample, the edge height is proportional to the total amount of the element in the sample, ${ }^{32,33}$ and enables in situ monitoring of the dissolution of the sample. The change in edge height of the spectra with applied potentials is plotted in Figure 7 (blue curve), together with the change in white line intensity (red curve). The edge height is almost constant at low potentials, but it starts to fall above $1.6 \mathrm{~V}$, which is almost coincident with the decrease in white line intensity. We should note that the onset potential of the vigorous oxygen evolution reaction (OER) of Pt nanoparticle catalyst is also around $1.8 \mathrm{~V} .{ }^{34}$

The fall in edge height can be attributed to a loss of Pt, which is most likely caused by dissolution of the Pt oxide. Through the OER at the high potentials, local acidification takes place at the Pt surfaces (reaction 5).

$$
2 \mathrm{H}_{2} \mathrm{O} \rightarrow \mathrm{O}_{2}+4 \mathrm{H}^{+}+4 \mathrm{e}^{-}
$$

Although corrosion of carbon is reasonably low at potentials lower than $0.9 \mathrm{~V}$, it is inevitable under such the high potentials (reaction 6). ${ }^{35}$ 


$$
\mathrm{C}+\mathrm{H}_{2} \mathrm{O} \rightarrow \mathrm{CO}_{2}+4 \mathrm{H}^{+}+4 \mathrm{e}^{-}
$$

Both the reactions increase the concentration of $\mathrm{H}^{+}$with increasing potentials, thereby reducing local $\mathrm{pH}$ near the Pt surface. Consequently, the high local acidification may induce the dissolution of $\mathrm{PtO}_{2}$ as follow:

$$
\mathrm{PtO}_{2}+4 \mathrm{H}^{+} \rightarrow \mathrm{Pt}^{4+}+2 \mathrm{H}_{2} \mathrm{O}
$$

The loss of Pt through $\mathrm{PtO}_{2}$ dissolution decreases both the edge height and the intensity of white line above $1.9 \mathrm{~V}$. It was reported that the solubility of $\mathrm{PtO}_{2}$ is approximately 2.5 $\times 10^{-7} \mathrm{M}$ in $0.1 \mathrm{M} \mathrm{HClO}_{4}$ at $25^{\circ} \mathrm{C}$, and it increases in proportion to the $\left[\mathrm{H}^{+}\right]{ }^{36}$ A simple model using Nernst's approach is employed to calculate a proton concentration near the $\mathrm{PtO}_{2}$ surface under the OER and carbon corrosion (Figure S7). The estimated $\left[\mathrm{H}^{+}\right]$at $2.37 \mathrm{~V}$ is approximately $5 \mathrm{M}$, which is 50 times larger than the bulk concentration $(0.1 \mathrm{M}$ $\mathrm{HClO}_{4}$ ), and thereby the dissolution of $\mathrm{PtO}_{2}$ must be considerably enhanced. We consider that the oxide formation takes place simultaneously, but the $\mathrm{PtO}_{2}$ dissolution is more dominant under such the harsh condition. The present work confirmed that no thick $\mathrm{PtO}_{2}$ layers (> 2 layers) were formed within the potential range examined (up to $2.6 \mathrm{~V}$ ). The possible mechanisms of Pt oxide formation and dissolution are schematically illustrated in Figure 7.

Furthermore, smaller Pt particles may dissolve preferentially because of their size as their chemical potential is higher than that of larger particles, and thus the larger particles may remain. ${ }^{37}$ Since the ratio of surface atoms to total atoms of nanoparticles decreases with an increase in particle size, ${ }^{38}$ the ratio of Pt oxide to Pt metal becomes relatively smaller. As a consequence, the white line intensity becomes lower. 
The other explanation is via detachment of the oxidized Pt nanoparticles and electrolyte contact with depth in the carbon support. Corrosion of carbon support, coupled with vigorous stirring action of the electrolyte by the OER, may cause detachment of the oxidized Pt nanoparticles to the electrolyte, leaving unoxidzed Pt particles in depth. This too would decreases in both the white line intensity and the edge height.

\section{In situ XAS of Pt ML on Pd nanoparticle catalyst}

The Pt ML approach has several unique features, such as high Pt utilization and enhanced activity, making it very attractive for practical applications and resolving the problems of high Pt content and low activity in conventional electrocatalysts. ${ }^{22}$ Membrane electrode assembly (MEA) tests of the Pt ML electrocatalysts also demonstrated exceptional longterm stability. ${ }^{39,40}$ The atomic structure of the $\mathrm{Pt}_{\mathrm{ML}} / \mathrm{Pd} / \mathrm{C}$ electrocatalyst was examined using in situ EXAFS, and the formation of Pt MLs on Pd nanoparticle surfaces and the contraction in Pt-Pt distance were confirmed. ${ }^{20}$ The EXAFS analysis also demonstrated that the Pt ML structure was almost retained after 60,000 potential cycles in MEA tests. ${ }^{36}$ In situ XAS studies provide information only from the Pt ML atoms on the surface of the metal nanoparticles that participate in electrocatalytic reactions; thus, direct and unambiguous comparison between electronic/structural properties of a catalyst and its activity can be made.

In situ XANES spectra for $\mathrm{Pt}_{2}$ edge of a carbon-supported $\mathrm{Pt}_{\mathrm{ML}} / \mathrm{Pd} / \mathrm{C}$ catalyst at potentials ascending from $0.41 \mathrm{~V}$ to $1.51 \mathrm{~V}$ also show three distinct isosbestic points at the same potentials for the $\mathrm{Pt} / \mathrm{C}$ catalyst (at $11573 \mathrm{eV}, 11603 \mathrm{eV}$, and $11624 \mathrm{eV}$ as designated by arrows in Figure S8), demonstrating that the Pt ML is oxidized from 
metallic Pt toward a form of $\alpha-\mathrm{PtO}_{2}$, too. Figure 8 shows that the increase in white line intensity of $\mathrm{Pt}_{\mathrm{ML}} / \mathrm{Pd} / \mathrm{C}$ with potentials is much smaller (approximately a half in magnitude) than that of the $\mathrm{Pt} / \mathrm{C}$ sample, which is a clear evidence of the delayed oxidation of $\mathrm{Pt}_{\mathrm{ML}} / \mathrm{Pd} / \mathrm{C}$ compared with the $\mathrm{Pt} / \mathrm{C}$ catalyst.

We should note that in situ XAS spectra from the Pt/C catalyst are derived from both the surface and bulk Pt atoms, but the bulk atoms, which are $48 \%$ of the total atoms for nanoparticles with a diameter of $2.6 \mathrm{~nm}$ (Table S1), do not take part in the reaction. On the other hand, all the Pt atoms involved in the reaction are sampled for in situ XAS from the Pt ML catalyst. Let us compare percentages of oxide formation per surface Pt atoms between $\mathrm{Pt} / \mathrm{C}$ (Figure $4 \mathrm{~b}$ ) and $\mathrm{Pt}_{\mathrm{ML}} / \mathrm{Pd} / \mathrm{C}$ (Figure 9), which are derived from the fitting by the LCA. The comparison is shown in Figure S9. Above $1 \mathrm{~V}$, the $\mathrm{PtO}_{2}$ percentage per surface $\mathrm{Pt}$ atoms for $\mathrm{Pt}_{\mathrm{ML}} / \mathrm{Pd} / \mathrm{C}$ is $c a$. 3.5 times lower than that for $\mathrm{Pt} / \mathrm{C}$, and again significant retardation of Pt oxidation in Pt ML is demonstrated.

In situ XANES and Fourier transform (FT) EXAFS spectra for Pd K edge of the $\mathrm{Pt}_{\mathrm{ML}} / \mathrm{Pd} / \mathrm{C}$ catalyst at different potentials (from $0.41 \mathrm{~V}$ to $1.31 \mathrm{~V}$ ) are depicted in Figure S10, together with those of the PdO sample. The peaks around $1.6 \AA$ in Figure S10b reflect the formation of Pd oxide, which gradually increases with elevating potentials. The LCA technique was employed to determine the PdO percentage per Pd core metals and the $\mathrm{PtO}_{2}$ percentage per surface Pt atoms in $\mathrm{Pt}_{\mathrm{ML}} / \mathrm{Pd} / \mathrm{C}$ (note that the $\mathrm{N}_{\mathrm{s}} / \mathrm{N}_{\mathrm{t}}$ is $c a .0 .30$ for nanoparticles with a diameter of $4.2 \mathrm{~nm}$, as shown in Table S1), and the results are plotted as a function of applied potentials in Figure 9. In the regime up to $0.91 \mathrm{~V}, \mathrm{Pt}$ oxide growth on the Pt ML is negligible, while Pd in the Pd core already starts to be oxidized (e.g., $2.6 \%$ at $0.91 \mathrm{~V}$ ). In the previous studies, we envisaged that $\mathrm{PdOH}$ (or 
$\mathrm{PdO}$ ), which is negatively charged, is more easily formed at defects and/or pin-holes of Pt MLs than $\mathrm{PtOH}$ (or $\mathrm{PtO}$ ) and repulsion between $\mathrm{PdOH}$ and $\mathrm{PtOH}$ retards the oxidation of Pt MLs. ${ }^{19,22,41}$ The present result corroborates our proposition of the role of PdOH in suppressing a PtOH formation.

At potentials above $1.0 \mathrm{~V}$, the oxidation of both Pt and Pd increases. Particularly interesting is the behavior of Pd oxidation; since Pd cores are covered by Pt MLs, basically Pd atoms are not exposed to the solution. Therefore, we consider that Pd oxides grow inward through the defects in Pt MLs and/or by oxygen penetrated through Pt MLs. In the latter case, Pd oxidation is caused by the place-exchange process between $\mathrm{O}$ and $\mathrm{Pt}$ in MLs. In the regime over $1 \mathrm{~V}$, the preferential Pd oxidation presumably prevents the oxidation of Pt MLs, and thus it imparts a certain degree of cathodic protection for Pt MLs. ${ }^{36,37}$ At $1.51 \mathrm{~V}$, the percentage of the oxide formation in Pt MLs is $21 \%$, which is 3.6 times smaller than that of Pt/C (76 \% in Figure 4b. See also Figure S9). On the other hand, at the same potential the percentage of $\mathrm{PdO}$ in Pd cores is $15 \%$, which corresponds to $34 \%$ of Pd atoms on the surface of Pd cores (assuming that Pd oxidation occurs exclusively through the place-exchange mechanism and the $\mathrm{N}_{\mathrm{s}} / \mathrm{N}_{\mathrm{t}}$ is ca. 0.44 for nanoparticles with a diameter of $3.7 \mathrm{~nm}$ ). As shown in Table S1, the number of surface atoms with a diameter of 4.16 is 492, and thus 103 atoms $(492 \times 0.21)$ in the Pt MLs are oxidized. Similarly, the number of surface atoms with a diameter of 3.61 is 362, and thus 123 atoms $(362 \times 0.34)$ in the Pd core surface are oxidized. Assuming that Pt in the MLs and Pd in the surface core form their oxides with subsurface $\mathrm{O}$, the remaining $20 \mathrm{Pd}$ atoms (123 - 103) are oxidized at defects and/or pinholes of Pt MLs. In MEA tests, the Pt ML on Pd nanoparticle electrocatalyst endured 100,000 potential cycles, during which 
no considerable loss of Pt was observed, whereas Pd underwent considerable dissolution from the cores, resulting in hollow structures. ${ }^{39}$ The present study suggests the preferential Pd oxidation proceeds at the defects in Pt MLs up to $0.91 \mathrm{~V}$ and through $\mathrm{O}$ penetrated through the Pt MLs by the place exchange process over $1.11 \mathrm{~V}$, thereby leading to the protection of the surface Pt MLs. In the future we will investigate behavior of oxidation of $\mathrm{Pt}_{\mathrm{ML}} / \mathrm{Pd} / \mathrm{C}$ at higher potentials above $1.5 \mathrm{~V}$ using the cell II, to see if the Pt ML may starts to dissolve like the Pt/C sample as discussed above or the preferential Pd oxidation/dissolution still retards the oxidation/dissolution of Pt MLs.

\section{Conclusions}

By combining in situ XAS and XRD measurements we examined the detailed oxidation process of Pt nanoparticle electrocatalyst in a wide range of applied potentials from $0.4 \mathrm{~V}$ to 2.6 V. Pt nanoparticle surfaces are oxidized from metallic Pt to $\alpha-\mathrm{PtO}_{2}$-type oxide during the potential sweep up to $1.5 \mathrm{~V}$, although the oxidation is confined to take place only at the top layer of nanoparticles. The $\Delta \mu$ method revealed the transition state of $\mathrm{O}$ or $\mathrm{OH}$ adsorption (at $0.71 \mathrm{~V}$ ) on Pt surfaces and the onset of the place exchange process (at $0.91 \mathrm{~V}$ ). At higher potentials above $1.9 \mathrm{~V}$, the $\alpha-\mathrm{PtO}_{2}$-type oxide starts to dissolve due to local high acidification caused by the OER and carbon corrosion. Corrosion of carbon support may also cause detachment of the oxidized Pt nanoparticles to the electrolyte, leaving unoxidzed Pt particles in depth. The mechanism of oxidation process of $\mathrm{Pt}_{\mathrm{ML}} / \mathrm{Pd} / \mathrm{C}$ is quite different from that of $\mathrm{Pt} / \mathrm{C}$. The Pt MLs are protected presumably because preferential Pd oxidation proceeds at the defects in Pt MLs up to $0.91 \mathrm{~V}$ and through $\mathrm{O}$ penetrated through the Pt MLs by the place exchange process above $1.11 \mathrm{~V}$. 


\section{Supporting Information}

The Supporting Information is available free of charge on the ACS Publications website at http://pubs.acs.org.

TEM image of $\mathrm{Pt}_{\mathrm{ML}} / \mathrm{Pd} / \mathrm{C}, \mathrm{XRD}$ patterns of $\mathrm{PtO}_{2}$ and $\mathrm{PdO}$, white lines of L3 edge from Pt/C, Pt L3 edge height, oxide formation from cyclic voltammograms, in situ XANES of $\mathrm{Pt}_{\mathrm{ML}} / \mathrm{Pd} / \mathrm{C}, \mathrm{PtO}_{2}$ percentages in $\mathrm{Pt} / \mathrm{C}$ and $\mathrm{Pt}_{\mathrm{ML}} / \mathrm{Pd} / \mathrm{C}$, in situ $\mathrm{XAS}$ of $\mathrm{Pd} \mathrm{K}$ edge of $\mathrm{Pt}_{\mathrm{ML}} / \mathrm{Pd} / \mathrm{C}$, and a table listing the particle size and coordination numbers of Pt nanoparticles

\section{Author Information}

Corresponding Author: Kotaro Sasaki, ksasaki@bnl.gov

\section{Author Contributions}

K.S., N.M., H.S.I., and R.R.A. contributed equally.

\section{Notes}

The authors declare no competing financial interests.

\section{Acknowledgements}

This research was performed at Brookhaven National laboratory under contract DESC0012704 with the US Department of Energy, Office of Basic Energy Science, Material Science and Engineering Division, Division of Chemical Sciences, Geosciences and Biosciences Division. Beamlines X18A, X18B, and X19A at the NSLS, as well as B2-2 
at the SSRL were supported in part by the Synchrotron Catalysis Consortium, U. S. Department of Energy Grant No DE-SC0012335.

\section{References}

$1 \quad$ Debe, M. K. Nature 2012, 486, 43-51.

2 Sasaki, K.; Shao, M.; Adzic, R. R. In Polymer Electrolyte Fuel Cell Durability; Buhchi, F. N.; Inaba, M.; Schmidt, T.J. Eds.; Springer: New York, 2009; pp 89110.

3 Gottesfeld, S. In Fuel Cell Catalysis: A Surface Science Approach; Koper, M. T. M. Ed.; Wiley: Hoboken, NJ, 2009; pp 1-30.

4 Gasteiger, H. A.; Kocha, S. S.; Sompalli, B.; Wagner, F. T. Appl. Catal., B 2005, B56, 9-35.

5 Topalov, A. A.; Serhiy Cherevko, S.; Zeradjanin, A. R.; Meier, J. C.; Katsounaros, I.; Mayrhofer, K. J. J.Chem. Sci.2014, 5, 631-638.

6 Jovanovič, P.; Pavlišič, A.; Šelih, V. S.; Šala, M.; Hodnik, N.; Bele, M.; Hočevar, S.; Gaberšček, M.ChemCatChem 2014, 6, 449-453.

$7 \quad$ Conway, B. E. Progress in Surface Science 1995, 49, 331-345.

8 Angerstein-Kozlowska, H.; Conway, B. E.; Sharp, W. B. A. J. Electroanal. Chem. 1973, 43, 9-36.

9 Harrington, D. A. J. Electroanal. Chem. 1997, 420, 101-109.

10 Birss, V. I.; Chang, M.; Segal, J. J. Electroanal. Chem. 1993, 355, 181-191.

11 Jerkiewicz, G.; Vatankhah, G.; Lessard, J.; Soriaga, M. P.; Park, Y. S. Electrochim. Acta 2004, 49, 1451-1459.

12 Jerkiewicz, G. In Interfacial Electrochemistry; Wieckowski, A. Ed.; Marcel Dekker: New York, 1999; pp 559-576.

13 Mukerjee, S.; McBreen, J.; Reilly, J. J.; Johnson, J. R.; Adzic, G.; Petrov, K.; Kumar, M. P. S.; Zhang, W.; Srinivasan, S. J. Electrochem. Soc. 1995, 142, 2278-2286.

14 Tada, M.; Murata, S.; Asakoka, T.; Hiroshima, K.; Okumura, K.; Tanida, H.; Uruga, T.; Nakanishi, H.; Matsumoto, S.; Inada, Y.; Nomura, M.; Iwasawa, Y. Angew. Chem. Int. Ed. 2007, 46, 4310-4315.

15 Nagasawa, K.; Takao, S.; Higashi, K.; Nagamatsu, S.; Samjeske, G.; Imaizumi, Y.; Sekizawa, O.; Yamamoto, T.; Uruga, T.; Iwasawa, Y. Phys. Chem. Chem. Phys. 2013, 16, 10075-10087.

16 Nagamatsu, S.; Arai, T.; Yamamoto, M.; Ohkura, T.; Oyanagi, H.; Ishizaka, T.; Kawanami, H.; Uruga, T.; Tada, M.; Iwasawa Y. J. Phys. Chem. C 2013, 117, 13094-13107.

17 Imai, H.; Izumi, K.; Matsumoto, M.; Kubo,Y.; Kato, K.; Imai, Y. J. Am. Chem. Soc. 2009, 131, 6293-6300.

18 Kongkanand, A.; Ziegelbauer, J. M. J. Phys. Chem. C 2012, 116, 3684-3693. 
19 Friebel, D.; Miller, D. J.; O’Grady, C. P.; Anniyev, T.; Bargar, J.; Bergmann, U.; Ogasawara, H.; Wikfeldt, K. T.; Pettersson, L. G. M.; Nilsson, A. Phys. Chem. Chem. Phys. 2011, 13, 262-266.

20 Sasaki, K.; Wang, J. X.; Naohara, H.; Marinkovic, N.; More, K.; Inada, H.; Adzic, R. R. Electrochim. Acta 2010, 55, 2645-2652.

21 Sasaki, K.; Adzic, R. R. Synchrotron Radiat. News 2009, 22, 17-21.

22 Adzic, R. R.; Zhang, J; Sasaki, K.; Vukmirovic, M.B.; Shao, M.; Wang, J.X.; Nilekar, A.U.; Mavrikakis, M.; Valerio, J. A.; Uribe, F. Top. Catal. 2007, 46, 249-262.

23 Brankovic, S. R.; Wang, J. X.; Adzic, R. R. Surf. Sci. 2001, 477, L173-L179.

24 Zhang, J.; Mo, Y.; Vukmirovic, M. B.; Klie, R.; Sasaki, K.; Adzic, R. R. J. Phys. Chem. B 2004, 108, 10955-10964.

25 Gao, M.-R.; Lin, Z.-Y.; Jiang, J.; Cui, C.-H.; Zheng, Y.-R.; Yu, S.-H. Chem. Eur. J. 2012, 18, 8423-8429.

26 McBreen, J.; O'Grady, W. E.; Pandya, K. I.; Hoffman, R. W.; Sayers, D. E. Langmuir 1987, 3, 428-433.

27 Ravel, B.; Newville, M. Synchrotron Radiat. 2005, 12, 537-541.

28 Teliska, M.; O'Grady, W. E.; Ramaker, D. E. J. Phys. Chem. B 2005, 109, 80768084.

29 Arruda, T. M.; Shyam, B.; Ziegelbauer, J. M.; Mukerjee, S.; Ramaker, D. E. J. Phys. Chem. C 2008, 112, 18087-18097.

30 Ramaker, D. E.; Koningsbergerb, D. C. Phys. Chem. Chem. Phys. 2010, 12, 5514-5534.

31 Nagy, Z.; You, H. Electrochim. Acta 2002, 47, 3037-3055.

32 Virtanen, S.; Schmuki, P.; Isaacs, H. S. Electrochim. Acta 2002, 47, 3117-3125.

33 Davenport, A. J.; Isaacs, H. S.; Bardwell, J. A.; MacDougall, B.; Frankel, G. S.;

Schrott, A. G. Corros. Sci. 1993, 35, 19-25.

34 Reier, T.; Oezaslan, M.; Strasser, P. ACS Catal. 2012, 2, 1765-1772.

35 Kinoshita, K. In Carbon: Electrochemical and Physicochemical Properties; Wiley: New York, 1988; pp 20.

36 Mitsushima, S.; Koizumi, Y.; Uzuka, S.; Ota, K.-I. ECS Trans. 2007, 11, 11951201.

37 Virkar, A. V.; Zhou, Y. K. J. Electrochem. Soc. 2007, 154, B540-B546.

38 Benfield, R. E. J. Chem. Soc. Faraday Trans. 1992, 88, 1107-1110.

39 Sasaki, K.; Naohara, H.; Cai, Y.; Choi, Y. M.; Liu, P.; Vukmirovic, M. B.; Wang, J. X.; Adzic, R. R. Angew. Chem. Int. Ed. 2010, 49, 8602 -8607.

40 Sasaki, K.; Naohara, H.; Choi, Y. M.; Cai, Y.; Chen, W.-H.; Liu, P.; Adzic, R. R. Nat. Commun. 2012, 3, 1115.

41 Zhang, J.; Vukmirovic, M. B.; Sasaki, K.; Uribe, F.; Adzic, R. R. J. Serb. Chem. Soc. 2005, 70, 513-525. 


\section{$\underline{\text { Table of Contents }}$}

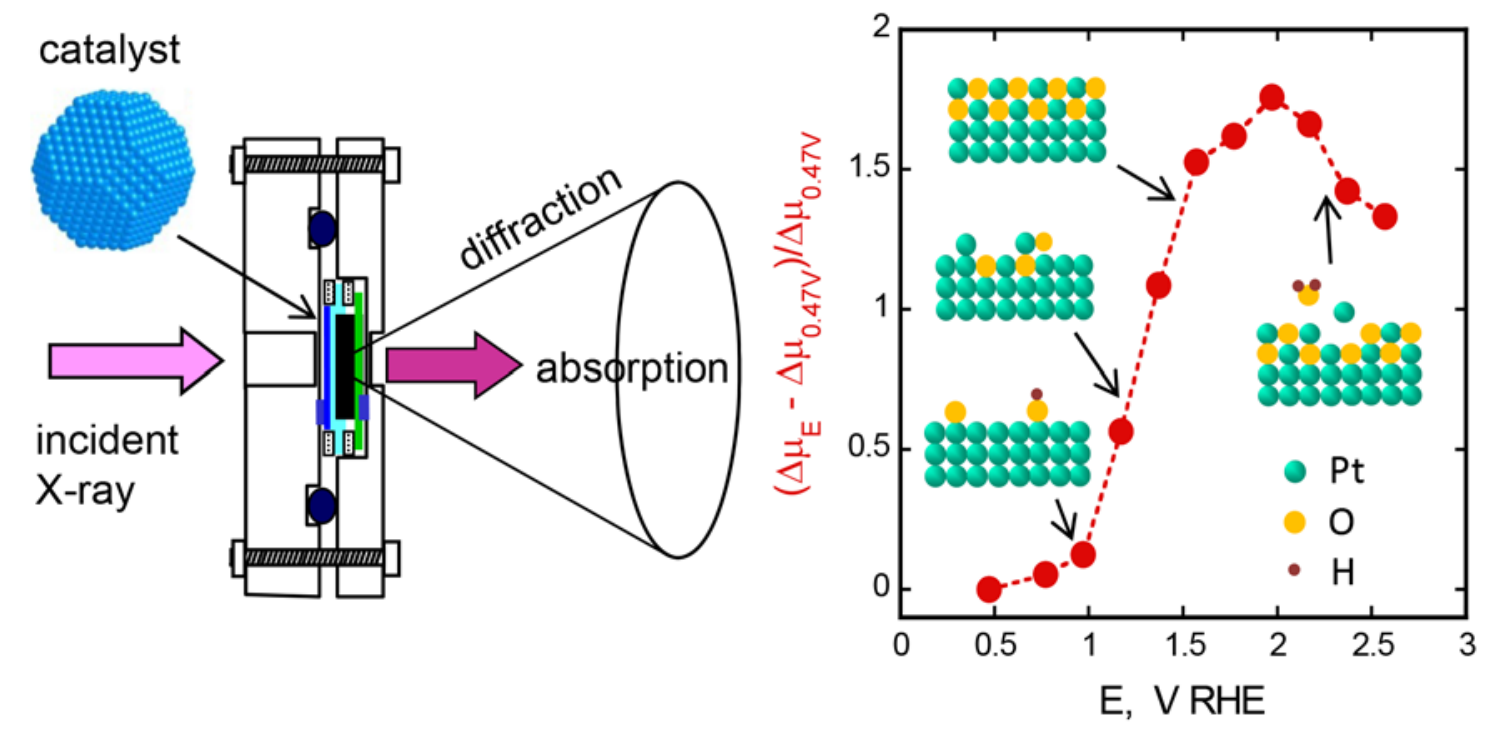




\section{Figures}
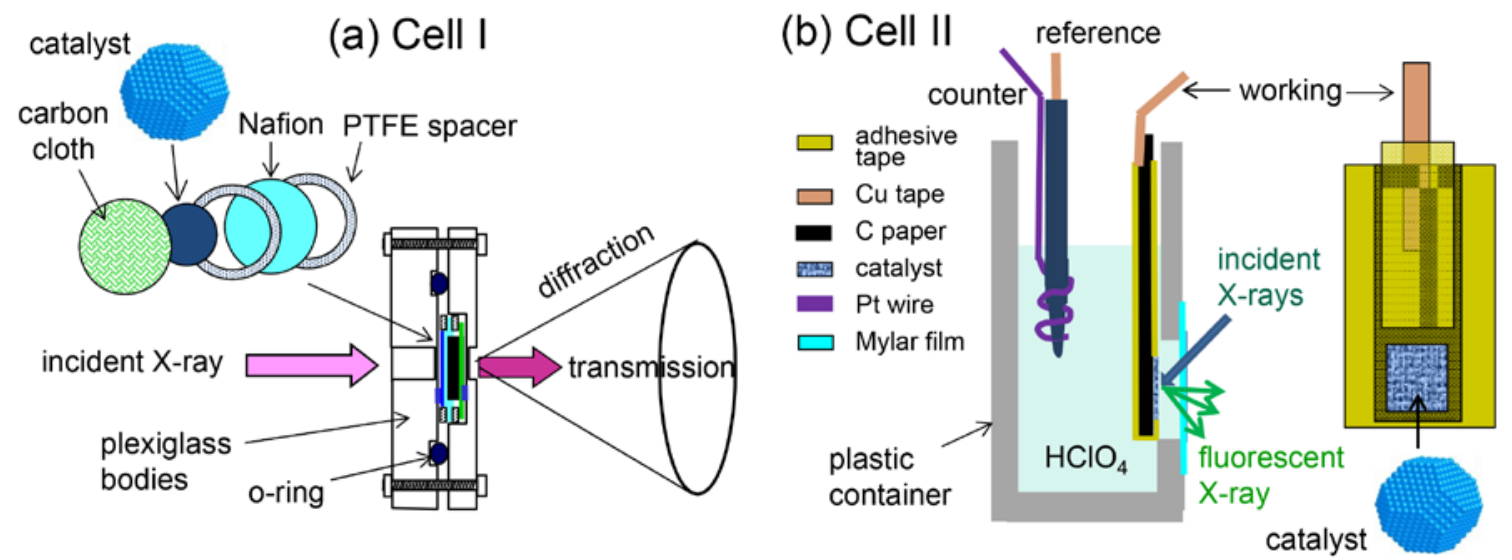

Figure 1. Schematic diagrams of in situ electrochemical (a) cell I and (b) cell II. 

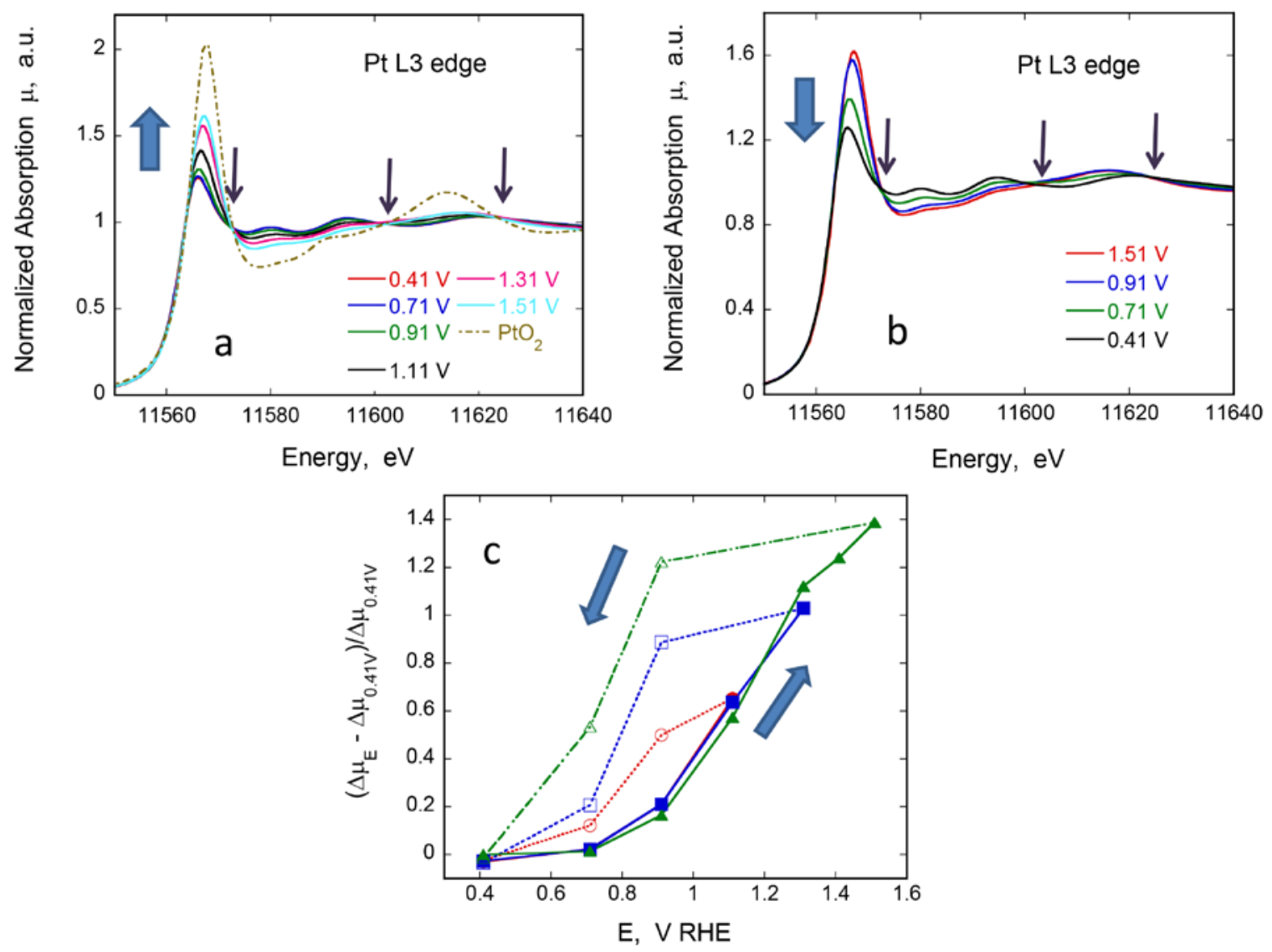

Figure 2. In situ XANES for $\mathrm{Pt} \mathrm{L}_{3}$ edge of carbon-supported Pt nanoparticles at potentials (a) ascending from 0.41 to $1.51 \mathrm{~V}$ and (b) descending from $1.51 \mathrm{~V}$ to $0.41 \mathrm{~V}$ in $1 \mathrm{M} \mathrm{HClO}_{4}$. Also shown (yellowish green dashed line) is ex situ XANES from commercial $\mathrm{PtO}_{2}$. Three distinct isosbestic points are observed at $11573 \mathrm{eV}, 11603 \mathrm{eV}$, and $11624 \mathrm{eV}$ as designated by arrows. (c) Relative changes in absorption peaks $\left(\left(\Delta \mu_{\mathrm{E}}-\right.\right.$ $\Delta \mu_{0.41 \mathrm{~V})} / \Delta \mu_{0.41 \mathrm{~V}}$, see Figure S4) at Pt L3 edge of the carbon-supported Pt nanoparticles during potential cycles with different upper potentials, plotted as a function of applied potentials. 

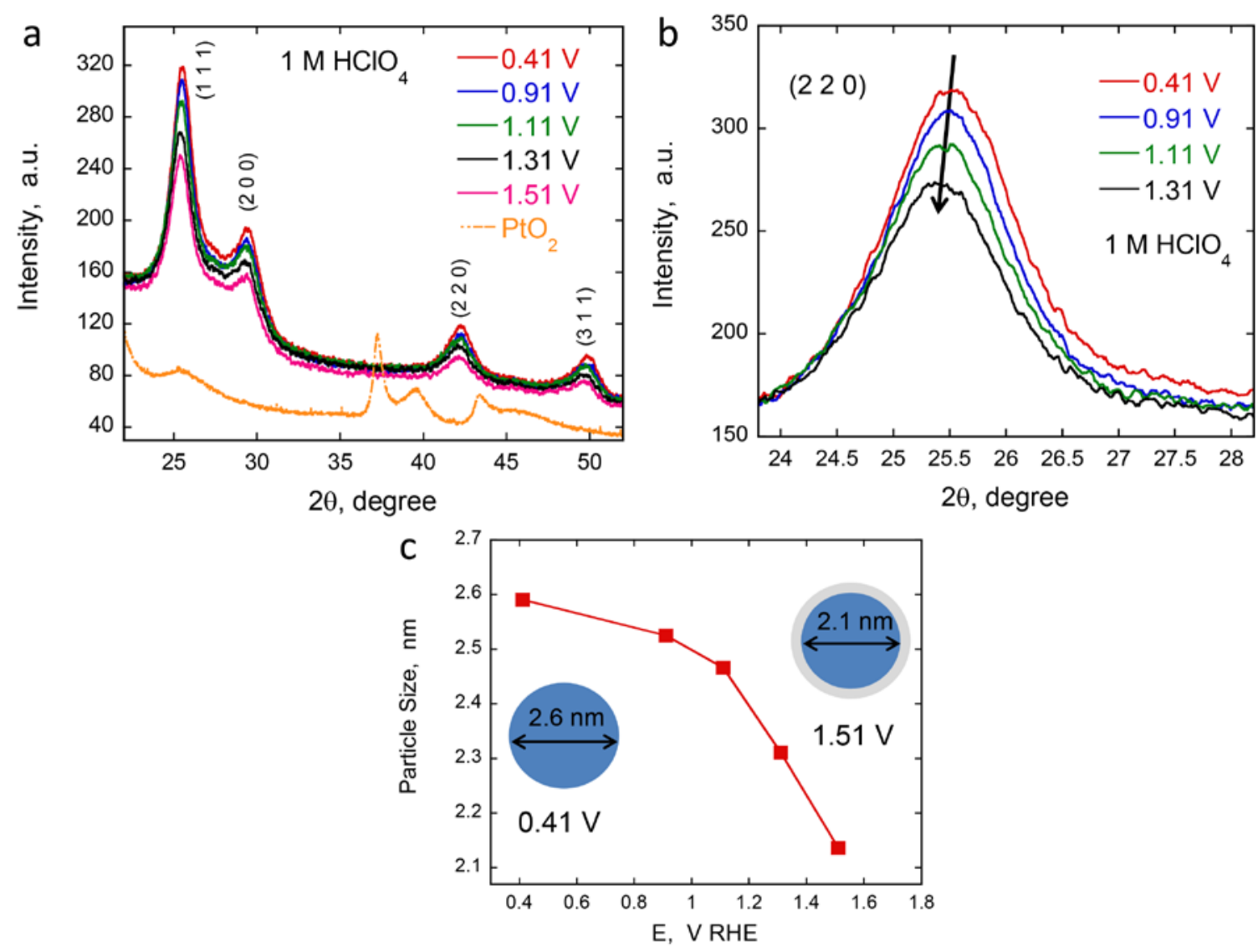

Figure 3. (a) In situ XRD of $\mathrm{Pt} / \mathrm{C}$ in $1 \mathrm{M} \mathrm{HClO}_{4}$ at increasing potentials from $0.41 \mathrm{~V}$ to $1.51 \mathrm{~V}$. Also shown is ex situ XRD of commercial $\mathrm{PtO}_{2}$ (with no potential applied). Wavelength: $1.000 \AA$. (b) Detailed patterns of the (2 2 0) reflection from a Pt/C catalyst. (c) Changes in particle size determined by Sherrer's equation, plotted as a function of applied potentials. 

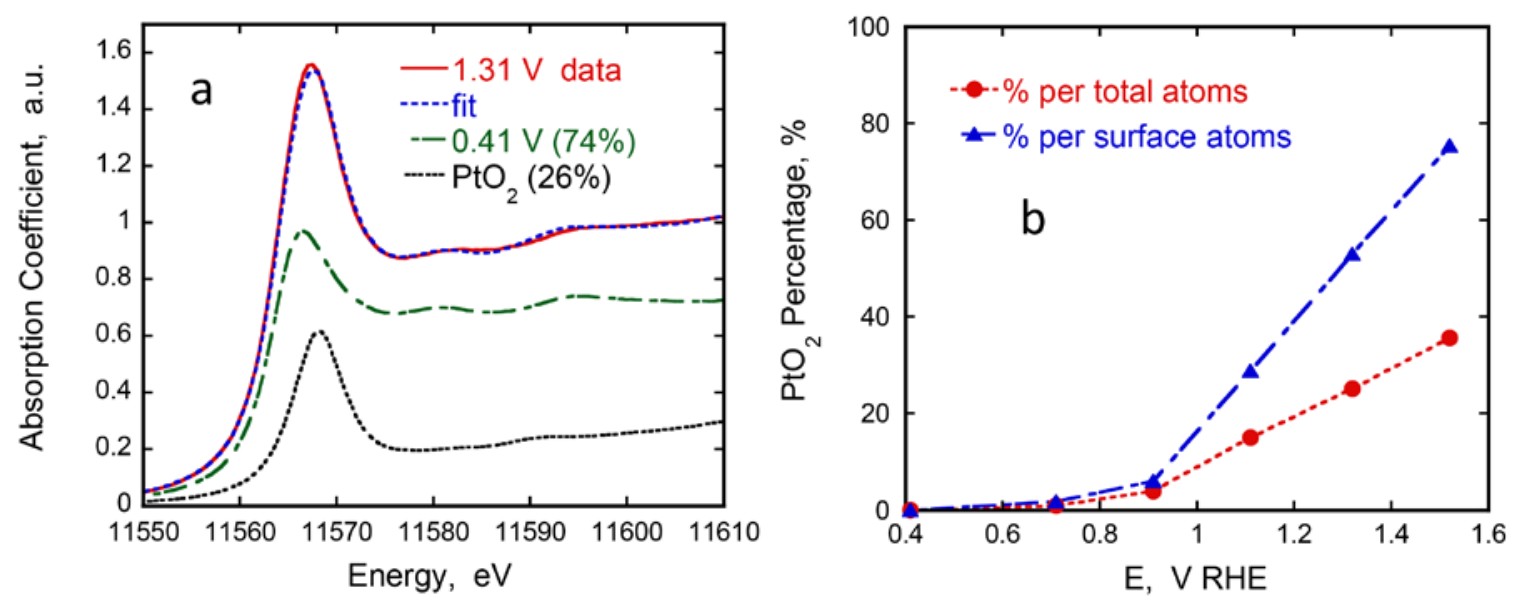

Figure 4. (a) Linear combination analysis (LCA) of Pt surface electrochemically oxidized at $1.31 \mathrm{~V}$, using the spectra of Pt surface in the same electrolyte where no Pt oxidation is expected $(0.41 \mathrm{~V})$ (green dotted-dash curve) and a commercial $\mathrm{PtO}_{2}$ standard (black dotted curve). (b) $\mathrm{PtO}_{2}$ percentages per total atoms (red) and per surface atoms (blue) plotted vs applied potentials. 


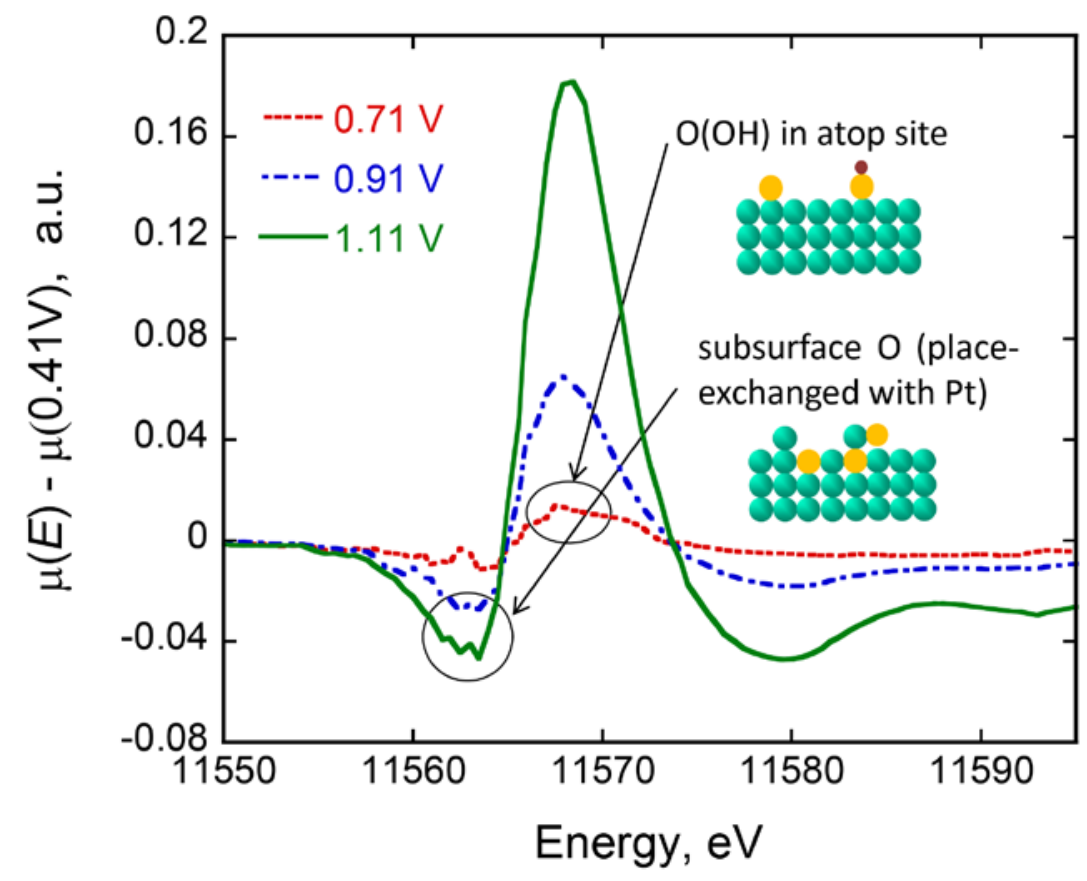

Figure 5. Pt $\mathrm{L}_{3}$ edge $\Delta \mu(E)(=\mu(E)-\mu(0.41 \mathrm{~V}))$ spectra of carbon-supported $\mathrm{Pt}$ nanoparticles at $E=0.71 \mathrm{~V}, 0.91 \mathrm{~V}$, and $1.11 \mathrm{~V}$ in $1 \mathrm{M} \mathrm{HClO}_{4}$. 


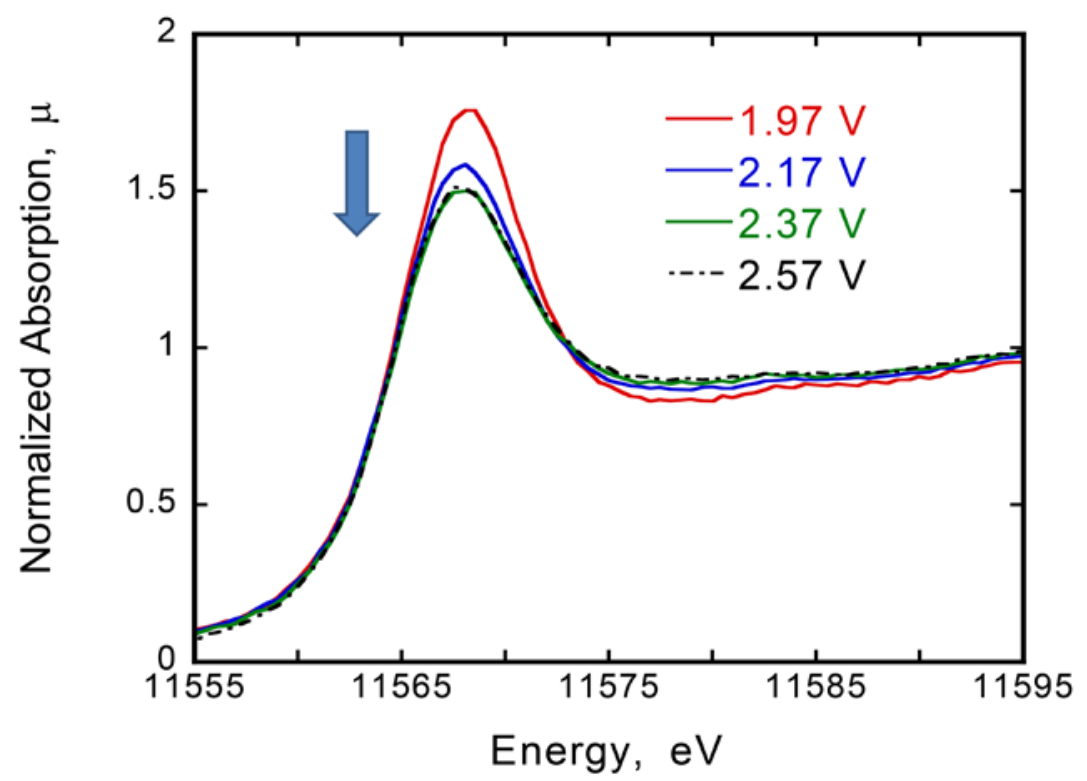

Figure 6. In situ XANES from the Pt/C catalyst using the cell II at potentials from $1.97 \mathrm{~V}$ and $2.57 \mathrm{~V}$. 


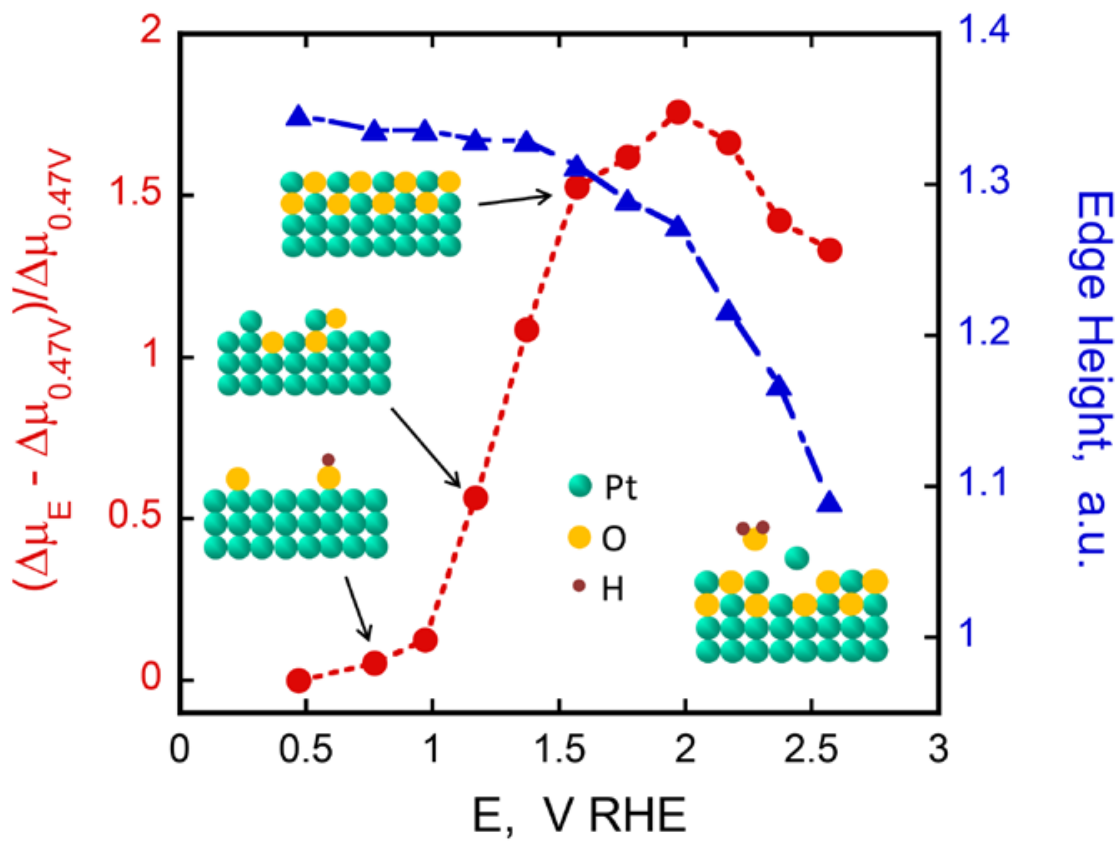

Figure 7. Changes in white line intensity observed in in situ XANES from the Pt/C catalyst using the cell II (red curve) and in edge height (blue curve) as a function of the applied potentials. Also shown are schematics of the process of Pt oxide formation and its dissolution. 


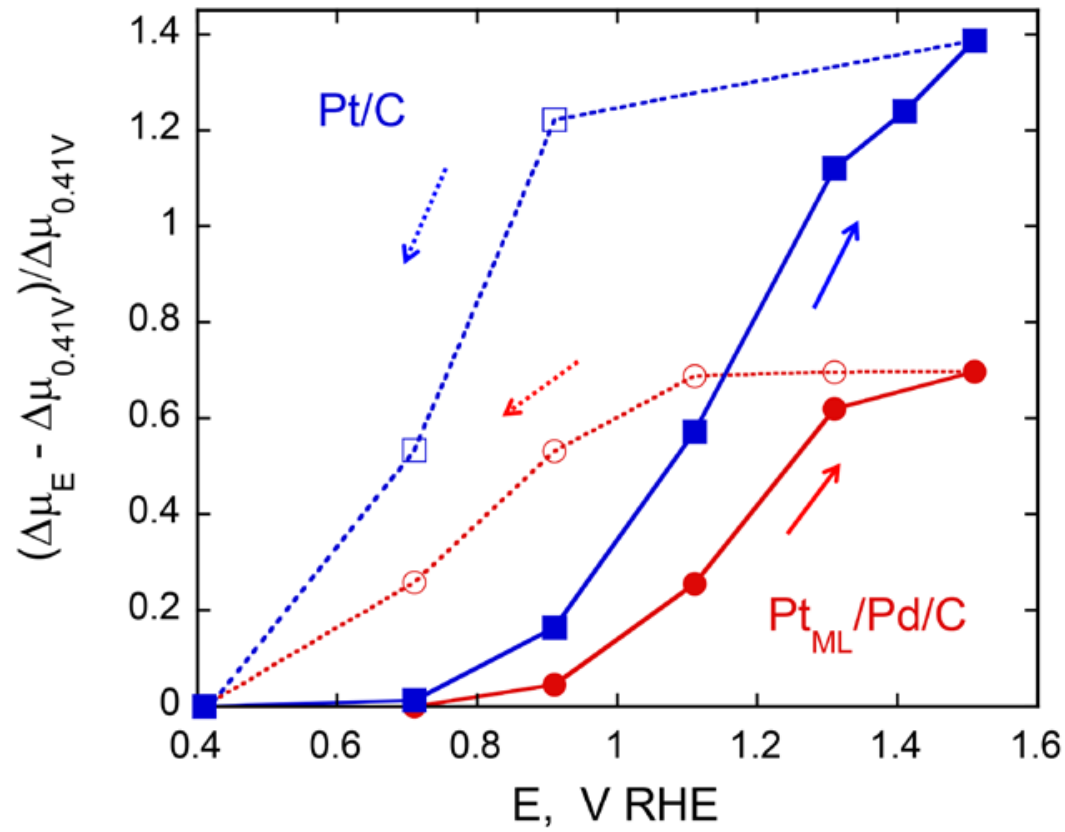

Figure 8. Relative changes in absorption peaks $\left.\left(\Delta \mu_{\mathrm{E}}-\Delta \mu_{0.41 \mathrm{~V}}\right) / \Delta \mu_{0.41 \mathrm{~V}}\right)$ at Pt $\mathrm{L}_{3}$ edge of $\mathrm{Pt}_{\mathrm{ML}} / \mathrm{Pd} / \mathrm{C}$ (red curve) during potential cycles plotted as a function of applied potentials. Also shown is that of $\mathrm{Pt} / \mathrm{C}$ (blue curve) presented in Figure 2c for comparison. 


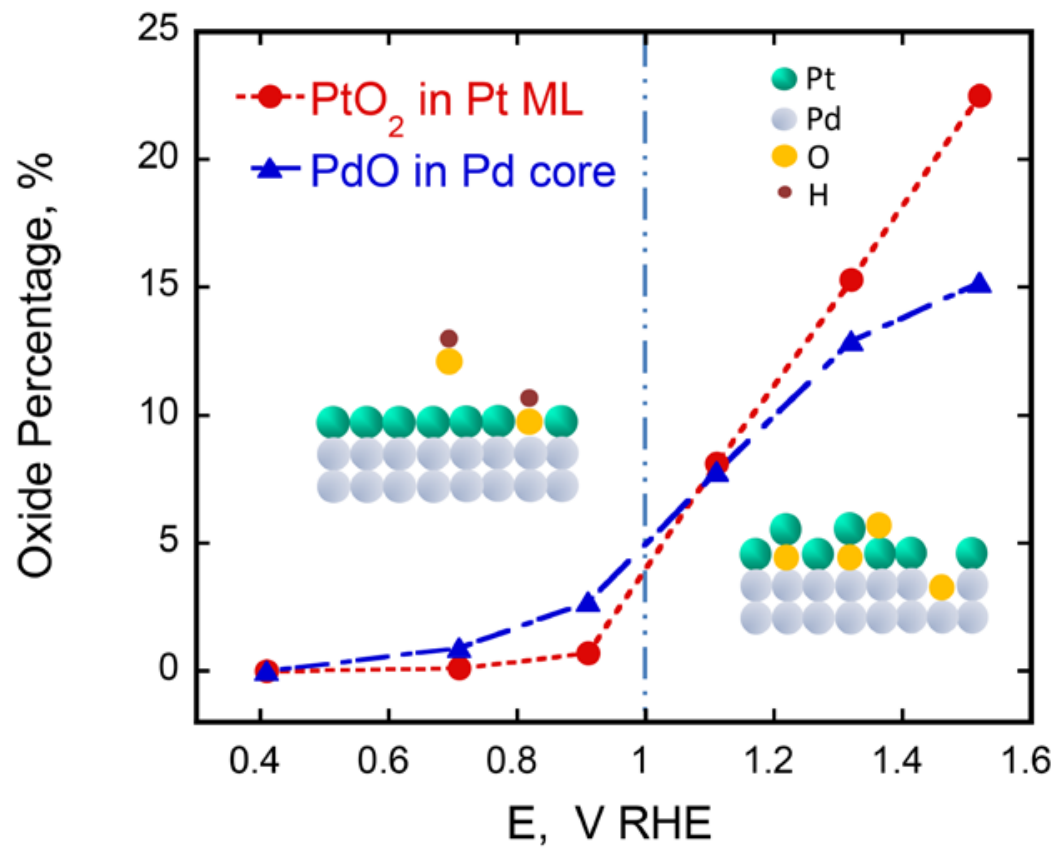

Figure 9. $\mathrm{PdO}$ percentage per $\mathrm{Pd}$ core metals (blue curve) and $\mathrm{PtO}_{2}$ percentage per surface $\mathrm{Pt}$ atoms (red curve) in $\mathrm{Pt}_{\mathrm{ML}} / \mathrm{Pd} / \mathrm{C}$ plotted as a function of applied potentials. 